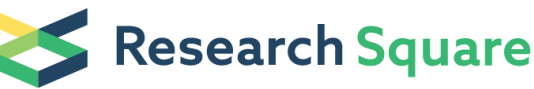 \\ Preprints are preliminary reports that have not undergone peer review. \\ They should not be considered conclusive, used to inform clinical practice, or referenced by the media as validated information.
}

\section{XAF1 is identified as a novel hub gene and associated with the clinical characteristics of lupus nephritis}

\section{Xingruo Zeng}

Department of Immunology, School of Basic Medical Science, Wuhan University, Wuhan, Hubei 430071, China

\section{Tian Xie}

Department of Immunology, School of Basic Medical Science, Wuhan University, Wuhan, Hubei 430071, China

\section{Jiaxing Sun}

Department of Immunology, School of Basic Medical Science, Wuhan University, Wuhan, Hubei 430071, China

\section{Yufei Lei}

Department of Immunology, School of Basic Medical Science, Wuhan University, Wuhan, Hubei 430071, China

\section{Lin Jia}

Department of Nephrology, The Central Hospital of Wuhan, Tongji Medical College, Huazhong University of Science and Technology, Wuhan, Hubei 430014, China

\section{Zimeng Wei}

Department of Immunology, School of Basic Medical Science, Wuhan University, Wuhan, Hubei 430071, China

\section{Muhammad Jamal}

Department of Immunology, School of Basic Medical Science, Wuhan University, Wuhan, Hubei 430071, China

\section{Hong Qin}

Department of Medical Insurance Management, Zhongnan Hospital of Wuhan University, Wuhan, China qiuping zhang ( $\nabla$ qpzhang@whu.edu.cn)

Department of Immunology, School of Basic Medical Science, Wuhan University, Wuhan, Hubei 430071, China Hubei Provincial Key Laboratory of Developmentally Originated Disease, Wuhan University, Wuhan, Hubei 430071, China

\section{Research}

Keywords: Lupus nephritis, Hub genes, XAF1, proteinuria, WHO Lupus Nephritis Class 
Posted Date: June 3rd, 2020

DOl: https://doi.org/10.21203/rs.3.rs-32319/v1

License: (c) (i) This work is licensed under a Creative Commons Attribution 4.0 International License. Read Full License 


\section{Abstract \\ Background}

Lupus nephritis (LN) is a severe complication of systemic lupus erythematosus (SLE) that is the most common cause of morbidity and mortality. At present, the definitive therapies towards $L N$ remains to be elucidated, so illuminating the molecular mechanism behind the disease has become an urgent task for researchers. This study set out to screen the hub genes of LN.

\section{Methods}

The microarray expression profile dataset GSE32591 from the Gene Expression Omnibus (GEO) database with 15 normal and $32 \mathrm{LN}$ samples was assessed in this study. Gene Ontology (GO) and Kyoto Encyclopedia of Genes and Genomes (KEGG) enrichment analyses were conducted on the LN-related differentially expressed genes (DEGs). The Nephroseq database was performed to identify correlation analysis between unexplored hub genes and clinical features of LN. Additionally, the expression of the candidate genes was detected in the kidney tissue by immunohistochemistry.

\section{Results}

The 14 genes (13 upregulated and 1 downregulated) ultimately screened out as candidate hub genes of the pathogenesis of LN. Moreover, Correlation analysis between the unexplored hub genes and clinical features of LN suggested that XAF1 may involve in the progression of LN. Finally, our data demonstrated that the expression level of XAF1 was upregulated in LN compared with IgA nephropathy (IgAN) and related to the WHO Lupus Nephritis Class and the quantitative $24 \mathrm{~h}$ proteinuria of LN patients.

\section{Conclusions}

The current study proposed XAF1 as a novel hub gene in LN which may perform as a brand-new biomarker or therapeutic target of $L N$ in the future.

\section{Background}

Systemic lupus erythematosus (SLE) is an autoimmune disease characterized by the loss of selftolerance and formation of nuclear auto-antibody and immune complexes resulting in inflammation of multiple organs. Over the past 10-20 years, with the advent of earlier diagnosis and recognition of disease, as well as the introduction of newer less toxic therapeutic measures, the mortality in SLE patients have certainly decreased[1]. However, increased mortality remains part of the natural history of lupus[2-4] and SLE patients still have two to five times the risk of death compared with the general population[1]. Lupus nephritis (LN) is one of most serious complication of SLE[5, 6] which affects up to 
$60 \%$ of SLE patients $[7,8]$ and is a major predictor of poor prognosis in patients with SLE. The development of LN involves multiple pathogenic pathways including aberrant apoptosis, autoantibody production, immune complex deposition and complement activation[9]. However, the local tissue effects are independent of hematopoietic cell influence, which are major contributors to end-organ damage in LN[10]. Thus, the pathogenesis involved in the local tissue damage should be of great concern and the therapies that limit tissue damage by targeting renal parenchymal cells may also prove useful in the treatment of LN. In spite of great progresses have been made in understanding pathogenesis of LN through the use of genetic variant identification, mouse models, gene expression studies, and epigenetic analyses, the pathogenesis of $L N$ remains unclear and also has been hampered by disease heterogeneity.

Recently, with the development of bioinformatics technology, the gene expression profiling analysis of the whole transcriptome has increasingly been used to explore the pathogenesis-associated genes, classify different types of disease and predict clinical outcome[11]. A series of bioinformatics analysis methods, including differentially expressed genes (DEGs) investigation, function and pathway enrichment analyses, as well as protein-protein interaction (PPI) network analyses, were performed based on gene expression profiles[11-14]. LN is an inflammatory condition of the kidneys that encompasses various patterns of renal disease including glomerular and tubulointerstitial pathology. In view of the crucial role for local tissue effects in the pathogenesis of LN, exploring the underlying mechanisms, and finding efficient therapeutic strategy for retarding renal damage are quite necessary.

The aim of this study is to identify common marker genes across glomerulus and tubulointerstitial in LN. We analyzed the gene expression in glomerulus and tubulointerstitial of LN using Gene Expression Omnibus (GEO) database, and eventually identified 14 hallmark genes which may be related to the pathogenesis of LN. Correlation analysis between the unexplored hub genes and clinical features of $L N$ suggested that XAF1 may be a novel hub gene involved in the progression of LN. Moreover, the immunohistochemistry results of LN patients' kidney biopsies demonstrated that the expression level of XAF1 is upregulated in LN group and related to the WHO Lupus Nephritis Class of LN and $24 \mathrm{~h}$ urine protein quantitation. The current study proposed XAF1 as a novel candidate gene in LN and may perform as a brand-new biomarker or therapeutic target of $L N$ in the future.

\section{Methods}

\section{The microarray dataset}

The microarray dataset GSE32591 was analyzed with the GPL14663: Affymetrix GeneChip Human Genome HG-U133A Custom CDF. A total of 47 samples were used in this dataset, including 15 healthy living donors and $32 \mathrm{LN}$ patients. Demographic, clinical, and histologic characteristics of these patients were no statistical difference in any parameters between the LN cohorts used in arrays and RT-PCR[15]. All specimens were kidney biopsy.

\section{Identification of DEGs}


The gene expression profiles GSE32591 were acquired from GEO database[15]. The array data of the dataset consists of 32 glomeruli and 32 tubulointerstitium from LN patients and 15 glomeruli and 15 tubulointerstitium from control living donors. DEG was obtained from GEO database by a way of GEO2R analysis (http://www.ncbi. nlm.nih.gov/geo/geo2r/). The adj. P $<0.05$ and $\mid \log 2 \mathrm{FCl}>1$ was set as DEGs cutoff criterion.

\section{Gene Ontology (GO) and Kyoto Encyclopedia of Genes and Genomes (KEGG) enrichment analyses of DEGs}

To predict the biological processes or pathways that DEGs may be involved in, GO and KEGG enrichment analyses of DEGs were performed by R package "clusterProfiler"[16]. GO can be divided into three parts: molecular function (MF), biological process (BP) and cellular component (CC). R package "ggplot2" was used to visualize $\mathrm{GO}$ terms and KEGG pathways.

\section{PPI network construction and module analysis}

The PPI network was predicted using Search Tool for the Retrieval of Interacting Genes (STRING; https://string-db.org/) (version 11.0) online database[17]. Analyzing the functional interactions between proteins may provide insights into the mechanisms of generation or development of diseases. In the present study, PPI network of DEGs was constructed using STRING database, and an interaction with a combined score $>0.9$ was considered statistically significant. Cytoscape (version 3.6.0) is an open source bioinformatics software platform for visualizing molecular interaction networks[18]. The plug-in Molecular Complex Detection (MCODE) (version 1.5.1) of Cytoscape is an APP for clustering a given network based on topology to find densely connected regions[19]. The PPI networks were drawn using Cytoscape and the most significant module in the PPI networks was identified using MCODE. The criteria for selection were as follows: MCODE scores $>5$, degree cut-off $=2$, node score cut-off $=0.2, \mathrm{k}$-score $=2$ and Max depth $=100$.

\section{Nephroseq analysis}

Nephroseq analysis (https://www.nephroseq.org/resource/login.html\#) is a platform to the academic for integrative data mining of genotype/phenotype data. Nephroseq combines a wealth of publicly available renal gene expression profiles, which is gathered and managed by an experienced term of data scientists, bioinformaticians, and nephrologist[20]. We performed analysis on human kidney biopsy samples of comparison of all genes in LN vs other diseases, and examined the function of unexplored hub genes.

\section{Human kidney sample preparation}

Eighteen LN and seventeen IgA nephropathy (IgAN) kidney tissues were collected from the Central Hospital of Wuhan. Kidney tissues were immediately snap-frozen in liquid nitrogen, and stored at $-80{ }^{\circ} \mathrm{C}$ for further usage. The present study was approved by the Ethics Committee of the Central Hospital of Wuhan. Written informed consents were obtained from all patients prior to enrollment in the study and anonymity was guaranteed. 


\section{Immunohistochemistry staining}

Kidney cryo-sections at 3- $\mu \mathrm{m}$ thickness were fixed for $15 \mathrm{~min}$ in $4 \%$ paraformaldehyde, followed by permeabilization with $0.2 \%$ Triton X-100 in $1 \times$ phosphate-buffered saline for $5 \mathrm{~min}$ at room temperature. After blocking with $2 \%$ donkey serum for $60 \mathrm{~min}$, the slides were immunostained with anti-XAF1 (cat: ab17204, Abcam Biotechnology, USA). Slides were viewed with an Olympus Epi-fluorescence microscope equipped with a digital camera.

\section{Statistical analysis}

SPSS version (v. 21.0) and GraphPad Prism (v. 8.0) were used for statistical analysis and generating figures. Unpaired t-test and one-way ANOVA followed by Dunnett's test was used to compare the expression of XAF1 in different groups. Pearson correlation analysis was used to analyze the correlation between XAF1 expression and clinical characteristics. $\mathrm{P}<0.05$ was considered statistically significant.

\section{Results}

\section{Identification of DEGs}

The gene expression profile of GSE32591 was used to screen out significant differently expressed genes (DEGs) in the glomeruli and the tubulointerstitial respectively. Using adj. $\mathrm{P}<0.05$ and $\| \log 2 \mathrm{FC} \mid>1$ as cutoff criterion, 351 DEGs (250 upregulated and 101 downregulated) were identified in the glomeruli (Fig. 1a), and 129 DEGs (104 upregulated and 25 downregulated) were identified in the tubulointerstitial (Fig. 1b).

\section{Functional and pathway enrichment analysis of DEGs}

To analyze the biological classification of DEGs, functional and pathway enrichment analyses were performed by using R package "clusterProfiler". In glomeruli, GO analysis results showed that changes in BP of DEGs were significantly enriched in response to virus and defense response to virus, negative regulation of viral life cycle, type I interferon signaling pathway, cellular response to type I interferon, negative regulation of viral process, response to type I interferon (Fig. 2a). Changes in CC of DEGs were mainly enriched in the secretory granule membrane, cytoplasmic vesicle lumen, vesicle lumen and membrane microdomain (Fig. 2a). Changes in MF were mainly enriched in inorganic acid binding, glycosaminoglycan binding and cytokine binding (Fig. 2a). As for the pathways in glomerulus, the results of KEGG enrichment analysis showed that DEGs were enriched in Influenza A, Tuberculosis, Staphylococcus aureus infection, Epstein-Barr virus infection, Phagosome (Fig. 2b).

In tubulointerstitial, GO analysis results showed that DEGs were enriched in various BPs, the top 5 terms were type I interferon signaling pathway, cellular response to type I interferon, response to type I interferon, response to virus, defense response to virus, response to interferon-gamma, negative regulation of viral process, regulation of multi-organism process (Fig. 2C). Changes in CC of DEGs were 
mainly enriched in MHC protein complex, blood microparticle, extracellular matrix (Fig. 2c). Changes in MF were mainly enriched in organic acid binding, glycosaminoglycan binding and cytokine binding (Fig. 2c). KEGG pathway analysis revealed that the DEGs were mainly enriched in Epstein-Barr virus infection (Fig. 2d).

\section{PPI network construction and module analysis}

The PPI network of DEGs in glomeruli was constructed with 195 nodes and 789 edges (Fig. S1a) and the most significant module was obtained using Cytoscape (Fig. 3a), while in tubulointerstitial, the PPI network of DEGs was constructed with 84 nodes and 481 edges (Fig. S1b) and the most significant module showed in Fig. 3b. There are 22 and 23 genes in the most significant modules of glomeruli (module 1) and tubulointerstitial (module 2), respectively.

\section{Hub gene selection and analysis}

A total of 24 genes in glomeruli (hub gene 1) and 23 genes in tubulointerstitial (hub gene 2) with degrees $\geq 20$ were identified. In our study, we selected the overlap genes of "module 1", "module 2", "hub gene 1" and "hub gene 2" as shown in the Venn diagram. The results showed that 14 DEGs, including 13 upregulated genes (IFITM1, IFIT1, IFI6, IFITM3, ISG15, MX2, XAF1, IFIT3, IFIT2, RSAD2, OAS1, IFI27, MX1) and 1 down-regulated genes (EGR1), were the common genes between these four groups, and were identified as hub genes for further investigation (Fig. 4a). The gene symbols, full names, implications, and expression changes of these 14 hub genes are shown in Table 1. 
Table 1

The gene symbols, full names, implications, and expression changes of the hub genes

\begin{tabular}{|c|c|c|c|c|}
\hline \multicolumn{2}{|c|}{ Gene symbols } & \multirow{2}{*}{$\begin{array}{l}\text { Full name } \\
\text { Interferon-induced } \\
\text { transmembrane } \\
\text { protein } 1\end{array}$} & \multirow{2}{*}{$\begin{array}{l}\text { Implications } \\
\text { IFITM1 was found to be up-regulated in } \\
\text { platelets from SLE, which could affect platelet } \\
\text { activation and contribute to development of } \\
\text { vascular disease in SLE. }\end{array}$} & \multirow{2}{*}{$\begin{array}{l}\text { Change } \\
\text { up }\end{array}$} \\
\hline $\begin{array}{l}\text { IFITM } \\
\text { family }\end{array}$ & IFITM1 & & & \\
\hline & IFITM3 & $\begin{array}{l}\text { Interferon-induced } \\
\text { transmembrane } \\
\text { protein } 3\end{array}$ & $\begin{array}{l}\text { The association between IFITM3 and SLE/LN } \\
\text { has not been reported. }\end{array}$ & up \\
\hline \multirow[t]{3}{*}{$\begin{array}{l}\text { IFIT } \\
\text { family }\end{array}$} & IFIT1 & $\begin{array}{l}\text { Interferon-induced } \\
\text { protein with } \\
\text { tetratricopeptide } \\
\text { repeats } 1\end{array}$ & $\begin{array}{l}\text { IFIT1 is the first gene described as a candidate } \\
\text { gene for SLE and associated with podocytes } \\
\text { damage. }\end{array}$ & up \\
\hline & IFIT2 & $\begin{array}{l}\text { Interferon-induced } \\
\text { protein with } \\
\text { tetratricopeptide } \\
\text { repeats } 2\end{array}$ & $\begin{array}{l}\text { The expression of IFIT2 is up-regulation in SLE } \\
\text { patients and associated with SLE disease } \\
\text { activity. }\end{array}$ & up \\
\hline & IFIT3 & $\begin{array}{l}\text { Interferon-induced } \\
\text { protein with } \\
\text { tetratricopeptide } \\
\text { repeats } 3\end{array}$ & $\begin{array}{l}\text { IFIT3 is one of the genes that contributes to the } \\
\text { overactive CGAS/STING signaling pathway in } \\
\text { human SLE monocytes. }\end{array}$ & up \\
\hline \multirow[t]{3}{*}{$\begin{array}{l}\text { MX } \\
\text { family }\end{array}$} & MX1 & $\begin{array}{l}\text { Myxovirus } \\
\text { resistance protein } \\
1\end{array}$ & $\begin{array}{l}\text { MX1 is a potential marker for the diagnosis of } \\
\text { SLE in the peripheral blood and also for the } \\
\text { activity of lupus nephritis in the kidney. }\end{array}$ & up \\
\hline & MX2 & $\begin{array}{l}\text { Myxovirus } \\
\text { resistance protein } \\
2\end{array}$ & $\begin{array}{l}\text { MX2 was found to be up-regulated in glomeruli } \\
\text { from LN patients. }\end{array}$ & up \\
\hline & ISG15 & $\begin{array}{l}\text { Ubiquitin-like } \\
\text { protein ISG15 }\end{array}$ & $\begin{array}{l}\text { ISG15 expression is higher in SLE patients with } \\
\text { lymphocytopenia and glomeruli from LN } \\
\text { patients. }\end{array}$ & up \\
\hline \multirow[t]{4}{*}{$\begin{array}{l}\text { FAM4 } \\
\text { family }\end{array}$} & IFI6 & $\begin{array}{l}\text { Interferon alpha- } \\
\text { inducible protein } 6\end{array}$ & $\begin{array}{l}\text { The expression of IFI6 is up-regulation in SLE } \\
\text { patients. }\end{array}$ & up \\
\hline & $\mathrm{IFI} 27$ & $\begin{array}{l}\text { Interferon alpha- } \\
\text { inducible protein } \\
27\end{array}$ & $\begin{array}{l}\text { The expression of IFI } 27 \text { is up-regulation in SLE } \\
\text { patients. }\end{array}$ & up \\
\hline & RSAD2 & $\begin{array}{l}\text { Radical S- } \\
\text { adenosyl } \\
\text { methionine } \\
\text { domain-containing } \\
\text { protein } 2\end{array}$ & $\begin{array}{l}\text { RSAD2 significantly upregulated in SLE } \\
\text { patients compared with healthy donors. }\end{array}$ & up \\
\hline & OAS1 & $\begin{array}{l}2 \text { '-5'- } \\
\text { oligoadenylate } \\
\text { synthase } 1\end{array}$ & $\begin{array}{l}\text { Expression levels of OAS1 were significantly } \\
\text { higher in SLE patients than in normal and the } \\
\text { rheumatic disease controls. }\end{array}$ & up \\
\hline
\end{tabular}




\begin{tabular}{|clll|}
\hline Gene symbols & Full name & Implications & Change \\
\hline XAF1 & $\begin{array}{l}\text { XIAP-associated } \\
\text { factor 1 }\end{array}$ & $\begin{array}{l}\text { The association between XAF1 and SLE/LN } \\
\text { has not been reported. }\end{array}$ & up \\
\hline EGR1 & $\begin{array}{l}\text { Early growth } \\
\text { response protein 1 }\end{array}$ & $\begin{array}{l}\text { EGR1 is required for CD154 transcription in } \\
\text { primary CD4 T cells in SLE. }\end{array}$ & down \\
\hline
\end{tabular}

We further performed GO analysis of the 14 hub genes, with the criteria of adj. $\mathrm{P}<0.0001$ and $q$ value $<$ 0.0001 . Following these criteria, $18 \mathrm{GO}$ terms were significantly enriched (Fig. $4 \mathrm{~b})$. All the 14 genes were enriched in the type I interferon related terms (type I interferon signaling pathway, cellular response to type I interferon, response to type I interferon) (Table 2). 
Table 2

GO analysis of the 14 hub genes

\begin{tabular}{|c|c|c|c|c|c|}
\hline NO. & GO_ID & Term & p.adjust & $\mathrm{q}$ & Count \\
\hline 1 & GO:0060337 & type I interferon signaling pathway & $\begin{array}{l}2.18 \mathrm{e}- \\
31\end{array}$ & $\begin{array}{l}1.32 \mathrm{e}- \\
31\end{array}$ & 14 \\
\hline 2 & GO:0071357 & cellular response to type I interferon & $\begin{array}{l}2.18 \mathrm{e}- \\
31\end{array}$ & $\begin{array}{l}1.32 \mathrm{e}- \\
31\end{array}$ & 14 \\
\hline 3 & G0:0034340 & response to type I interferon & $\begin{array}{l}3.33 e- \\
31\end{array}$ & $\begin{array}{l}2.01 \mathrm{e}- \\
31\end{array}$ & 14 \\
\hline 4 & G0:0051607 & defense response to virus & $\begin{array}{l}7.34 \mathrm{e}- \\
20\end{array}$ & $\begin{array}{l}4.45 \mathrm{e}- \\
20\end{array}$ & 12 \\
\hline 5 & GO:0009615 & response to virus & $\begin{array}{l}3.06 \mathrm{e}^{-} \\
18\end{array}$ & $\begin{array}{l}1.85 \mathrm{e}- \\
18\end{array}$ & 12 \\
\hline 6 & GO:0045069 & regulation of viral genome replication & $\begin{array}{l}4.00 \mathrm{e}- \\
14\end{array}$ & $\begin{array}{l}2.42 \mathrm{e}- \\
14\end{array}$ & 8 \\
\hline 7 & GO:0045071 & negative regulation of viral genome replication & $1.81 \mathrm{e}^{-}$ & $1.10 \mathrm{e}-$ & 7 \\
\hline 8 & GO:0019079 & viral genome replication & $\begin{array}{l}2.62 e^{-} \\
13\end{array}$ & $1.58 \mathrm{e}-$ & 8 \\
\hline 9 & GO:1903900 & regulation of viral life cycle & $\begin{array}{l}1.01 \mathrm{e}^{-} \\
12\end{array}$ & $\begin{array}{l}6.13 e- \\
13\end{array}$ & 8 \\
\hline 10 & GO:1903901 & negative regulation of viral life cycle & $\begin{array}{l}1.96 \mathrm{e}- \\
12\end{array}$ & $1.19 \mathrm{e}$ & 7 \\
\hline 11 & GO:0050792 & regulation of viral process & $\begin{array}{l}5.49 e^{-} \\
12\end{array}$ & $\begin{array}{l}3.32 \mathrm{e}- \\
12\end{array}$ & 8 \\
\hline 12 & GO:0048525 & negative regulation of viral process & $\begin{array}{l}5.49 \mathrm{e}- \\
12\end{array}$ & $\begin{array}{l}3.32 \mathrm{e}- \\
12\end{array}$ & 7 \\
\hline 13 & G0:0043903 & $\begin{array}{l}\text { regulation of symbiosis, encompassing } \\
\text { mutualism through parasitism }\end{array}$ & $\begin{array}{l}1.43 e- \\
11\end{array}$ & $\begin{array}{l}8.69 \mathrm{e}- \\
12\end{array}$ & 8 \\
\hline 14 & GO:0035455 & response to interferon-alpha & $\begin{array}{l}4.37 e- \\
11\end{array}$ & $\begin{array}{l}2.65 \mathrm{e}- \\
11\end{array}$ & 5 \\
\hline 15 & GO:0019058 & viral life cycle & $\begin{array}{l}2.13 e- \\
10\end{array}$ & $\begin{array}{l}1.29 \mathrm{e}- \\
10\end{array}$ & 8 \\
\hline 16 & GO:0035456 & response to interferon-beta & $\begin{array}{l}2.42 \mathrm{e}- \\
10\end{array}$ & $\begin{array}{l}1.46 \mathrm{e}- \\
10\end{array}$ & 5 \\
\hline 17 & G0:0043901 & negative regulation of multi-organism process & $\begin{array}{l}3.21 \mathrm{e}- \\
10\end{array}$ & $\begin{array}{l}1.94 \mathrm{e}- \\
10\end{array}$ & 7 \\
\hline
\end{tabular}




\begin{tabular}{|llllll|}
\hline NO. & GO_ID & Term & p.adjust & $\begin{array}{l}\text { q } \\
\text { value }\end{array}$ & Count \\
\hline 18 & G0:0043900 & regulation of multi-organism process & $\begin{array}{l}1.30 \mathrm{e}- \\
09\end{array}$ & $\begin{array}{l}7.9 \mathrm{e}- \\
10\end{array}$ & 8 \\
\hline
\end{tabular}

\section{Analysis of the DEGs based on Nephroseq}

Based on the results from GEO databases and a series of analysis, we found that the important 14 genes may be involved in the pathogenesis of lupus nephritis. To further verify the induction of these 13 upregulated genes in LN, we analyzed the Nephroseq database based on Comparison of All Genes in Ju Chronic Kindey Disease Glomeruli (Ju CKD Glom) and tubulointerstitial (Ju CKD Tublnt) study, lupus nephritis vs other diseases. The dataset showed that the expression of these genes was also increased in the kidney glomeruli and tubulointerstitial of LN patients (Fig. 5a-b). Subsequently, the unexplored hub genes IFITM3 and XAF1 in SLE/LN were further analyzed. The correlation between unexplored hub genes and clinical manifestation was performed on Nephroseq online platform. We found that the expression of XAF1 increased in lupus mouse model with proteinuria compared with no proteinuria (Fig. $5 \mathrm{c}$ ).

\section{The expression of XAF1 in kidneys of lupus nephritis}

The above data illustrated that XAF1 may play an important role in the pathogenesis of LN. To verify the results of bioinformatics analysis, 35 human kidney biopsies were enrolled and included in the analysis. According to the pathological diagnosis, we identified cases of $18 \mathrm{LN}$ and $17 \operatorname{lgAN}$. On the basis of ISN/RPS classification, the patients with LN including 5 IV class, 1 (V+III) class, 8 (IV + V) class and $4 \mathrm{~V}$ class. The levels of serum creatinine, urea nitrogen and hematuresis show no significant difference between LN and IgAN patients, but proteinuria was higher in LN. The demographics, clinical and histological parameters of patients were showed in Table S1. In comparison with the IgAN group, the expression of XAF1 was upregulated in LN tissue by immunohisto- chemistry (Fig. 6a-b). In LN group, the expression of XAF1 is related to the WHO Lupus Nephritis Class, which was increased in Class V+IV LN and Class V LN compared to Class IV LN, respectively (Fig. 6c). Moreover, the expression of XAF1 shows a positive correlation with the quantitative $24 \mathrm{~h}$ proteinuria $(P<0.05)$ (Fig. $6 \mathrm{~d})$.

\section{Discussion}

LN is the most common severe complication of SLE[5] and contributes significantly to mortality in this disease[21, 22]. Despite currently available aggressive treatments, up to $50 \%$ of patients progress to endstage renal disease within 5 years of diagnosis $[21,22]$. As previously noted, most research and therapeutic target in clinical practice focus almost exclusively on glomerular pathology. More and more researches support the importance of tubulointerstitial inflammation in determining prognosis and patient outcomes[23-25]. Thus, kidney involvement in LN can affect either glomerular or tubulointerstitial compartments as well as combinations thereof. Here we used the bioinformatics analysis to identify the 
hub genes in glomerular and tubulointerstitial of LN. The hub genes could be used to elucidate the pathogenesis of this disease, and might be important biomarkers and/or therapeutic targets for $\mathrm{LN}$.

In our study, microarray dataset was used to identify the DEGs in both glomerular and tubulointerstitial of LN, and total of 351 DEGs (250 upregulated and 101 downregulated) and 129 DEGs (104 upregulated and 25 downregulated) were identified in glomerular and tubulointerstitial, respectively. Next, we predicted the DEGs functions based on GO and KEGG pathway enrichment analysis. Based on the PPI network, 14 DEGs, including 13 up-regulated and 1 down-regulated genes were recognized as hub genes.

Unexpectedly, GO analysis of the 14 hub genes showed that all these 14 genes were enriched in the type I IFN related terms. It is well documented that the type I IFN signature is a feature of LN. Increased level of IFN in serum of patients with SLE was already described 40 years ago and were later identified as type I IFN[26]. IFN is important in both the inflammatory process and development of damage in LN. Kidney biopsies of patients with SLE showed increased expression of IFN-inducible genes[27-30] and plasmacytoid dendritic cells accumulate in glomeruli of patients with active disease[31].

Type I IFN, as a central mediator in the pathogenesis of LN, may activate innate and adaptive immunity and intrarenal pathogenic mechanisms. Both direct and indirect effects of IFNs result from induction of a subset of genes, called IFN stimulated genes. The 13 up-regulated genes including IFITM1, IFIT1, IFI6, IFITM3, ISG15, MX2, XAF1, IFIT3, IFIT2, RSAD2, OAS1, IFI27, MX1, were almost IFN-inducible genes. The demonstration of a broad IFN-I-induced gene transcript signature in SLE PBMCs emerged from several laboratories[32,33]. Recent data from epigenetic analyses of hypomethylated genome sites support activation of many genes related to type I IFN signaling in SLE patients. IFIT1 is the first gene described as a candidate gene for SLE, and may function by activating Rho proteins through interaction with Rho/Rac guanine nucleotide exchange factor[34]. Wang $\mathrm{J}$, et al. have found that IFIT3 is one of the genes that contributes to the overactive cGAS/STING signaling pathway in human SLE monocytes[35]. IFITM1 were found to be up-regulated in platelets from SLE patients compared with healthy volunteers[36]. The ISG15 mRNA level was higher in whole blood cell counts of SLE patients when compared with the disease control and healthy control groups and ISG15 expression correlated with lymphocytopenia in active SLE patients[37]. The epigenome-wide DNA methylation study in lupus showed significant hypomethylation of differentially methylated sites was associated with several interferon-related genes, including MX1, IFI44L, IFIT1, RSAD2 and IRF7 in PBMCs[38]. However, the role of IFITM3 and XAF1 in SLE/LN has not been reported. In our study, XAF1 was found to be upregulated in both glomerular and tubulointerstitial of LN based on dataset GSE32591. Additionally, the clinical manifestation detection showed the XAF1 expression could be associated with proteinuria in the lupus mouse model. Therefore, we speculated that XAF1 participants in the progression of $\mathrm{LN}$, and may be a novel biomarker and therapeutic target for $L N$.

XAF1, a novel IFN stimulated gene, was identified in gene array studies in IFN-sensitive melanoma cells (WM9)[39]. XAF1 was discovered in a yeast two hybrid studies as a XIAP (X-linked inhibitor of apoptosis protein) -interacting protein[40] and seemed to function as a negative regulator of members of the IAP (inhibitor of apoptosis protein) family. Overexpression of XAF1 resulted in neutralization of XIAP's ability 
to inhibit cell death[40]. It is well known that, XAF1 as a proapoptotic tumor suppressor is always inactivated in multiple human cancers. XAF1 was identified ubiquitously in all normal adult and fetal tissues but was present in very low levels in a variety of cancer cell lines[41-45]. Both IFN- $\alpha 2$ and IFN- $\beta$ were found to induce XAF1 transcription. Type I IFN may therefore inhibit XIAP function by the induction of XAF1, and then negatively regulate the inhibitor of apoptosis. XAF1 was upregulated in whole peripheral blood from the Sjögren's syndrome patients compared with controls[46]. However, there have been no research about the role of XAF1 in SLE/LN progression. In this study, the immunostaining results showed that XAF1 was upregulated in the kidneys of LN compared with IgAN, and the XAF1 expression was associated with pathological type and the proteinuria. According to these results, it should be concluded that up-regulation and activation of XAF1 was specifically in LN and may participant in the progresses of LN. Moreover, the expression level of XAF1 was increased in Class V + IV LN and Class V LN compared to Class IV LN, respectively. The histopathologic class of LN was depended on the nature and exposure site of the autoantigens, immune complexes and complement cause injury in different compartments of the glomerulus[47]. Subendothelial immune complex and complement deposits cause vascular obstruction by endothelial cells (LN classes III and IV). Meanwhile, Subepithelial immune complex and complement deposits injure podocytes (membranous LN class $\mathrm{V}$ ), which promotes massive proteinuria and podocyte injure[48]. Therefore, we speculated that the expression of XAF1 might be induced by the subepithelial immune complex deposits in lupus kidney tissue and associated with podocyte injure. Meanwhile, the expression of XAF1 was positive correlation with quantitative $24 \mathrm{~h}$ proteinuria, which indicated that XAF1 may be implicated in the kidney filtration barrier and tubular reabsorption dysfunction.

\section{Conclusions}

In summary, the bioinformatics analysis indicated the up-regulation of XAF1 in kidney tissue may be involved in the pathogenesis of LN. Based on this finding, our further detection of renal tissue indicated that XAF1 was upregulated in the kidneys of LN compared with IgAN, and the expression of XAF1 was associated with pathological type and the proteinuria. Our study may highlight the novel biomarker and therapeutic targets for LN. However, regarding the limited patient number included in this study, the results are preliminary and more studies are still needed to further decipher the role of XAF1 involved in the pathogenesis of LN.

\section{Abbreviations}

SLE: Systemic lupus erythematosus; LN: Lupus nephritis; IgAN: IgA nephropathy. DEGs: differentially expressed genes; GO: Gene Ontology; KEGG: Kyoto Encyclopedia of Genes and Genomes; PPI: proteinprotein interaction; GEO: Gene Expression Omnibus; MF: molecular function; BP: biological process; CC: cellular component; MCODE: Molecular Complex Detection;

\section{Declarations}




\section{Ethics approval and consent to participate}

Informed consent was obtained from all participants included in the study. The study protocol complied with the Declaration of Helsinki and was approved by hospital's ethical review board (The Central Hospital of Wuhan, Wuhan, China).

\section{Consent for publication}

Not applicable.

\section{Availability of data and materials}

The datasets used and/or analyzed during the current study are available from the corresponding author upon reasonable request.

\section{Competing interests}

The authors declare that they have no competing interests.

\section{Funding}

This work was supported by the National Natural Science Foundation of China (Nos. 81770180) and Hubei Provincial Natural Science Fund for Creative Research Groups (2018CFA018).

\section{Authors' contributions}

QPZ designed and managed the whole research; XRZ, TX performed the experiments, analyzed the data and wrote the main manuscript text; XJS, YFL, ZMW, Jamal revised the manuscript; LJ provided professional advices about the research. All authors read and approved the final manuscript.

\section{Acknowledgements}

We thank all the medical staff from Department of Nephrology, Central Hospital of Wuhan, for their help on clinical data collection.

\section{References}

1. Fors Nieves CE, Izmirly PM. Mortality in Systemic Lupus Erythematosus: an Updated Review. Curr Rheumatol Rep. 2016;18:21-1.

2. Langefeld CD, Ainsworth HC, Cunninghame Graham DS, Kelly JA, Comeau ME, Marion MC, Howard TD, Ramos PS, Croker JA, Morris DL, et al. Transancestral mapping and genetic load in systemic 
lupus erythematosus. Nat Commun. 2017;8:16021.

3. Bruce IN, O'Keeffe AG, Farewell V, Hanly JG, Manzi S, Su L, Gladman DD, Bae SC, Sanchez-Guerrero J, Romero-Diaz J, et al. Factors associated with damage accrual in patients with systemic lupus erythematosus: results from the Systemic Lupus International Collaborating Clinics (SLICC) Inception Cohort. Ann Rheum Dis. 2015;74:1706-13.

4. Frodlund M, Reid S, Wettero J, Dahlstrom O, Sjowall C, Leonard D. The majority of Swedish systemic lupus erythematosus patients are still affected by irreversible organ impairment: factors related to damage accrual in two regional cohorts. Lupus. 2019;28:1261-72.

5. Davidson A. What is damaging the kidney in lupus nephritis? Nature reviews Rheumatology. 2016;12:143-53.

6. Yung $S$, Chan TM. Anti-DNA antibodies in the pathogenesis of lupus nephritis-the emerging mechanisms. Autoimmun rev. 2008;7:317-21.

7. Mohan C, Putterman C. Genetics and pathogenesis of systemic lupus erythematosus and lupus nephritis. Nat Rev Nephrol. 2015;11:329-41.

8. Durcan L, O'Dwyer T, Petri M. Management strategies and future directions for systemic lupus erythematosus in adults. Lancet. 2019;393:2332-43.

9. Yu F, Haas M, Glassock R, Zhao MH. Redefining lupus nephritis: clinical implications of pathophysiologic subtypes. Nat Rev Nephrol. 2017;13:483-95.

10. Tsokos GC, Lo MS, Costa Reis P, Sullivan KE. New insights into the immunopathogenesis of systemic lupus erythematosus. Nature reviews Rheumatology. 2016;12:716-30.

11. Gutiérrez NC, Sarasquete ME, Misiewicz-Krzeminska I, Delgado M, De Las Rivas J, Ticona FV, Fermiñán E, Martín-Jiménez P, Chillón $C$, Risueño A, et al. Deregulation of microRNA expression in the different genetic subtypes of multiple myeloma and correlation with gene expression profiling. Leukemia. 2010;24:629-37.

12. Li C, Zhou H, Zhang H, Wang S, Xu Y. Bioinformatics Analysis of Differential Innate Immune Signaling in Macrophages by Wild-Type Vaccinia Mature Virus and a Mutant Virus with a Deletion of the A26 Protein. Journal of virology. 2017;91:e01160-01117.

13. Eyre $S$, Orozco G, Worthington J. The genetics revolution in rheumatology: large scale genomic arrays and genetic mapping. Nature reviews Rheumatology. 2017;13:421-32.

14. Zhang G, Yang P. Bioinformatics Genes and Pathway Analysis for Chronic Neuropathic Pain after Spinal Cord Injury. BioMed research international. 2017;2017:6423021-1.

15. Berthier CC, Bethunaickan R, Gonzalez-Rivera T, Nair V, Ramanujam M, Zhang W, Bottinger EP, Segerer $\mathrm{S}$, Lindenmeyer $\mathrm{M}$, Cohen $\mathrm{CD}$, et al. Cross-species transcriptional network analysis defines shared inflammatory responses in murine and human lupus nephritis. J Immunol. 2012;189:988-1001.

16. Yu GC, Wang LG, Han YY, He QY. clusterProfiler: an R Package for Comparing Biological Themes Among Gene Clusters. Omics-a Journal of Integrative Biology. 2012;16:284-7. 
17. Szklarczyk D, Gable AL, Lyon D, Junge A, Wyder S, Huerta-Cepas J, Simonovic M, Doncheva NT, Morris JH, Bork P, et al. STRING v11: protein-protein association networks with increased coverage, supporting functional discovery in genome-wide experimental datasets. Nucleic Acids Res. 2019;47:D607-13.

18. Shannon P, Markiel A, Ozier O, Baliga NS, Wang JT, Ramage D, Amin N, Schwikowski B, Ideker T. Cytoscape: a software environment for integrated models of biomolecular interaction networks. Genome Res. 2003;13:2498-504.

19. Bader GD, Hogue CW. An automated method for finding molecular complexes in large protein interaction networks. Bmc Bioinformatics 2003, 4; doi:10.1186/1471-2105-4-2.

20. Liao MC, Zhao XP, Chang SY, Lo CS, Chenier I, Takano T, Ingelfinger JR, Zhang SL. AT2 R deficiency mediated podocyte loss via activation of ectopic hedgehog interacting protein (Hhip) gene expression. J Pathol. 2017;243:279-93.

21. Almaani S, Meara A, Rovin BH. Update on Lupus Nephritis. Clin J Am Soc Nephrol. 2017;12:825-35.

22. Gustafsson JT, Simard JF, Gunnarsson I, Elvin K, Lundberg IE, Hansson LO, Larsson A, Svenungsson E. Risk factors for cardiovascular mortality in patients with systemic lupus erythematosus, a prospective cohort study. Arthritis Res Ther. 2012;14:R46.

23. Yung S, Chan TM. Molecular and Immunological Basis of Tubulo-Interstitial Injury in Lupus Nephritis: a Comprehensive Review. Clin Rev Allergy Immunol. 2017;52:149-63.

24. Trotter K, Clark MR, Liarski VM. Overview of pathophysiology and treatment of human lupus nephritis. Curr Opin Rheumatol. 2016;28:460-7.

25. Yu F, Haas M, Glassock R, Zhao M-H. Redefining lupus nephritis: clinical implications of pathophysiologic subtypes. Nature reviews Nephrology. 2017;13:483-95.

26. Hooks JJ, Moutsopoulos HM, Geis SA, Stahl NI, Decker JL, Notkins AL. Immune interferon in the circulation of patients with autoimmune disease. N Engl J Med. 1979;301:5-8.

27. Watanabe S, Imaizumi T, Tsuruga K, Aizawa T, Ito T, Matsumiya T, Yoshida H, Joh K, Ito E, Tanaka H. Glomerular expression of myxovirus resistance protein 1 in human mesangial cells: possible activation of innate immunity in the pathogenesis of lupus nephritis. Nephrology (Carlton Vic). 2013;18:833-7.

28. Castellano G, Cafiero C, Divella C, Sallustio F, Gigante M, Pontrelli P, De Palma G, Rossini M, Grandaliano G, Gesualdo L. Local synthesis of interferon-alpha in lupus nephritis is associated with type I interferons signature and LMP7 induction in renal tubular epithelial cells. Arthritis research therapy. 2015;17:72-2.

29. Peterson KS, Huang JF, Zhu J, D'Agati V, Liu X, Miller N, Erlander MG, Jackson MR, Winchester RJ. Characterization of heterogeneity in the molecular pathogenesis of lupus nephritis from transcriptional profiles of laser-captured glomeruli. J Clin Invest. 2004;113:1722-33.

30. Shimizu Y, Yasuda S, Kimura T, Nishio S, Kono M, Ohmura K, Shimamura S, Kono M, Fujieda Y, Kato $M$, et al. Interferon-inducible $M \times 1$ protein is highly expressed in renal tissues from treatment-naïve 
lupus nephritis, but not in those under immunosuppressive treatment. Modern rheumatology. 2018;28:661-9.

31. Tucci M, Quatraro C, Lombardi L, Pellegrino C, Dammacco F, Silvestris F. Glomerular accumulation of plasmacytoid dendritic cells in active lupus nephritis: role of interleukin-18. Arthritis rheumatism. 2008;58:251-62.

32. Baechler EC, Batliwalla FM, Karypis G, Gaffney PM, Ortmann WA, Espe KJ, Shark KB, Grande WJ, Hughes KM, Kapur V, et al. Interferon-inducible gene expression signature in peripheral blood cells of patients with severe lupus. Proc Natl Acad Sci USA. 2003;100:2610-5.

33. Crow MK, Wohlgemuth J. Microarray analysis of gene expression in lupus. Arthritis research therapy. 2003;5:279-87.

34. Ye S, Pang H, Gu YY, Hua J, Chen XG, Bao CD, Wang Y, Zhang W, Qian J, Tsao BP, et al. Protein interaction for an interferon-inducible systemic lupus associated gene, IFIT1. Rheumatology. 2003;42:1155-63.

35. Wang J, Dai M, Cui Y, Hou G, Deng J, Gao X, Liao Z, Liu Y, Meng Y, Wu L, et al. Association of Abnormal Elevations in IFIT3 With Overactive Cyclic GMP-AMP Synthase/Stimulator of Interferon Genes Signaling in Human Systemic Lupus Erythematosus Monocytes. Arthritis rheumatology (Hoboken NJ). 2018;70:2036-45.

36. Lood C, Amisten S, Gullstrand B, Jönsen A, Allhorn M, Truedsson L, Sturfelt G, Erlinge D, Bengtsson AA. Platelet transcriptional profile and protein expression in patients with systemic lupus erythematosus: up-regulation of the type I interferon system is strongly associated with vascular disease. Blood. 2010;116:1951-7.

37. Yuan $Y, M a ~ H, ~ Y e ~ Z$, Jing W, Jiang Z. Interferon-stimulated gene 15 expression in systemic lupus erythematosus: Diagnostic value and association with lymphocytopenia. Z Rheumatol. 2018;77:256-62.

38. Joseph S, George NI, Green-Knox B, Treadwell EL, Word B, Yim S, Lyn-Cook B. Epigenome-wide association study of peripheral blood mononuclear cells in systemic lupus erythematosus: Identifying DNA methylation signatures associated with interferon-related genes based on ethnicity and SLEDAI. J Autoimmun. 2019;96:147-57.

39. Leaman DW, Chawla-Sarkar M, Vyas K, Reheman M, Tamai K, Toji S, Borden EC. Identification of Xlinked inhibitor of apoptosis-associated factor-1 as an interferon-stimulated gene that augments TRAIL Apo2L-induced apoptosis. J Biol Chem. 2002;277:28504-11.

40. Liston P, Fong WG, Kelly NL, Toji S, Miyazaki T, Conte D, Tamai K, Craig CG, McBurney MW, Korneluk RG. Identification of XAF1 as an antagonist of XIAP anti-Caspase activity. Nat Cell Biol. 2001;3:12833.

41. Jeong S-I, Kim J-W, Ko K-P, Ryu B-K, Lee M-G, Kim H-J, Chi S-G. XAF1 forms a positive feedback loop with IRF-1 to drive apoptotic stress response and suppress tumorigenesis. Cell death disease. 2018;9:806-6. 
42. Schluckebier L, Aran V, De Moraes J, Paiva H, Sternberg C, Ferreira CG. XAF1 expression levels in a non-small cell lung cancer cohort and its potential association with carcinogenesis. Oncol Rep. 2017;38:402-10.

43. Lee M-G, Han J, Jeong S-I, Her N-G, Lee J-H, Ha T-K, Kang M-J, Ryu B-K, Chi S-G. XAF1 directs apoptotic switch of p53 signaling through activation of HIPK2 and ZNF313. Proc Natl Acad Sci USA. 2014;111:15532-7.

44. Steigerwald C, Rasenberger B, Christmann M, Tomicic MT. Sensitization of colorectal cancer cells to irinotecan by the Survivin inhibitor LLP3 depends on XAF1 proficiency in the context of mutated p53. Arch Toxicol. 2018;92:2645-8.

45. Wu Q, Berglund AE, Wang D, MacAulay RJ, Mulé JJ, Etame AB. Paradoxical epigenetic regulation of XAF1 mediates plasticity towards adaptive resistance evolution in MGMT-methylated glioblastoma. Scientific reports. 2019;9:14072-2.

46. Yao Q, Song Z, Wang B, Qin Q, Zhang J-A. Identifying Key Genes and Functionally Enriched Pathways in Sjögren's Syndrome by Weighted Gene Co-Expression Network Analysis. Frontiers in genetics. 2019;10:1142-2.

47. Lech M, Anders HJ. The pathogenesis of lupus nephritis. J Am Soc Nephrol. 2013;24:1357-66.

48. Lorenz G, Anders HJ. Neutrophils, Dendritic Cells, Toll-Like Receptors, and Interferon-alpha in Lupus Nephritis. Semin Nephrol. 2015;35:410-26.

\section{Figures}
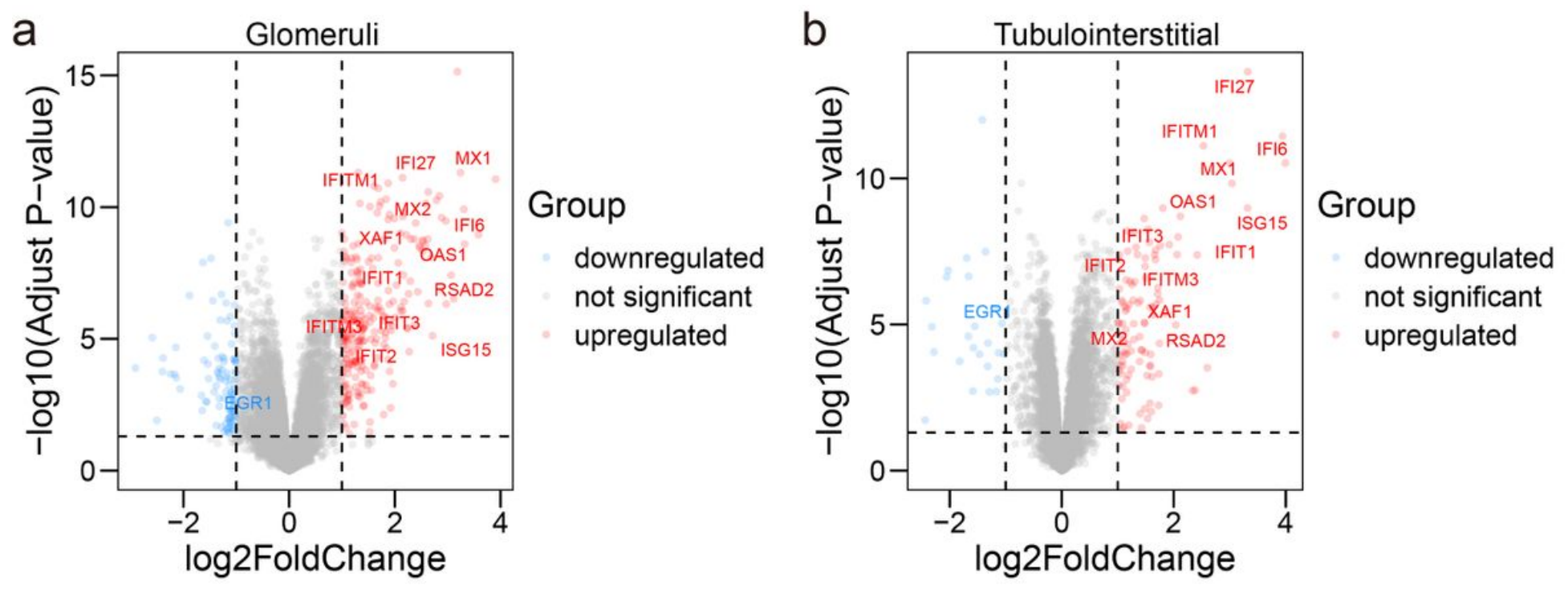

\section{Figure 1}

Identification of differentially expressed genes (DEGs) in lupus nephritis (LN). (a) The volcano plot of genes in LN glomeruli. (b) The volcano plot of genes in LN tubulointerstitial. Red dots represented upregulated DEGs, blue dots represented downregulated DEGs, and gray plots represented the rest of the 
genes with no significant expression change. Adj. $\mathrm{P}<0.05$ and $|\log 2 \mathrm{FC}|>1$ as cut-off criterion. DEGs, differentially expressed genes.

a
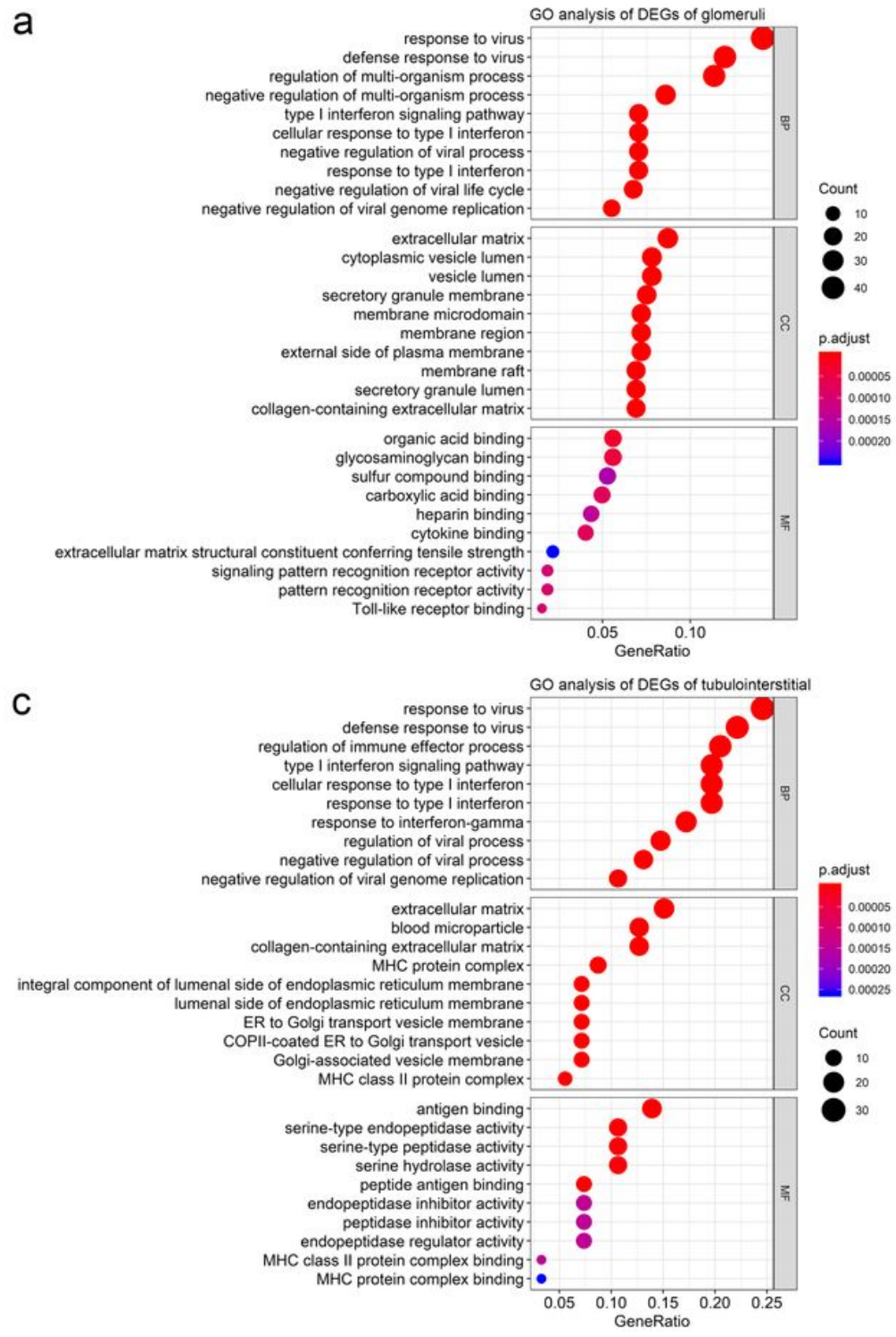

b

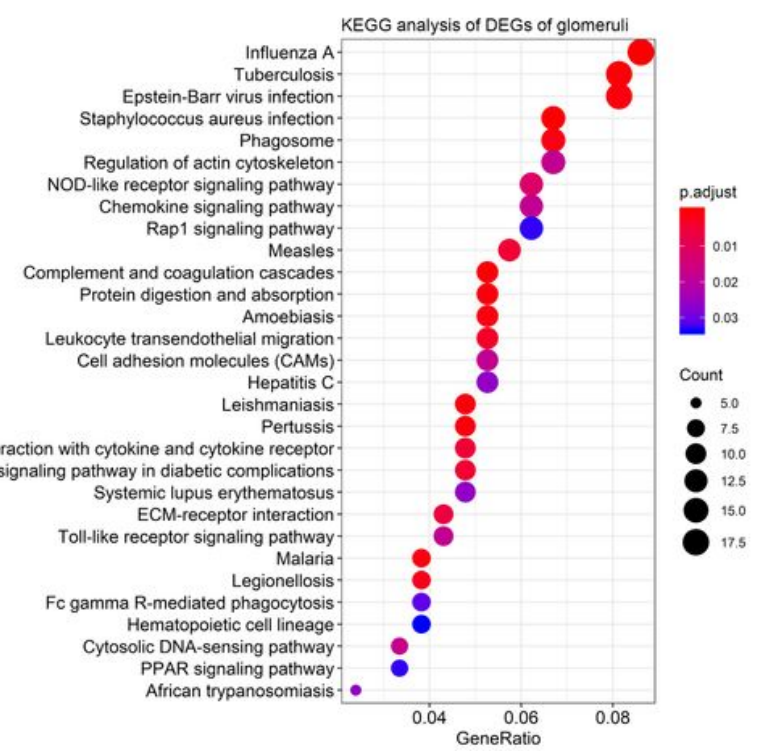

d

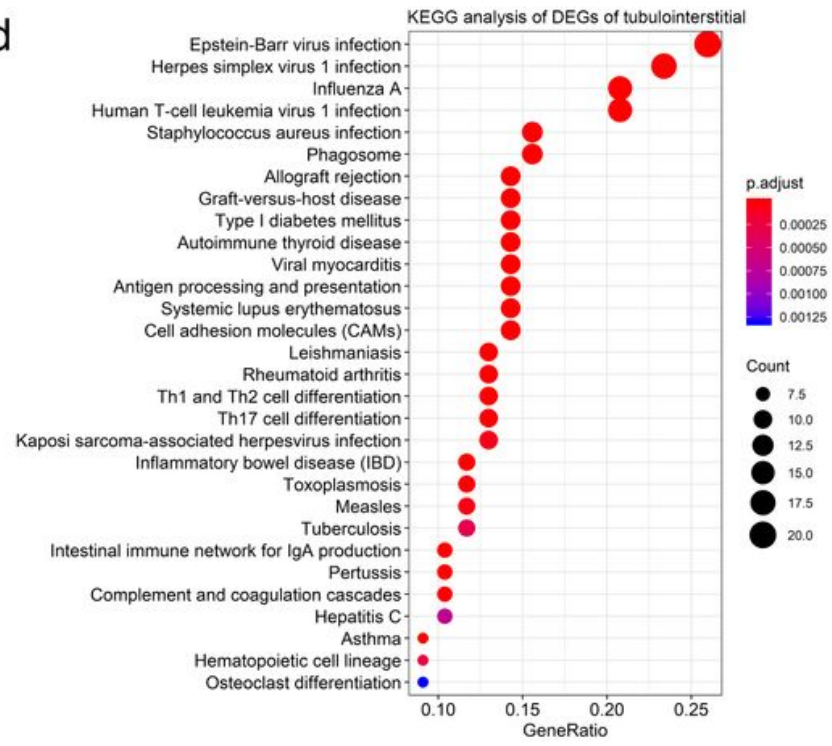

\section{Figure 2}

Functional and pathway enrichment analysis of DEGs. (a) GO analysis of DEGs of glomerulus. (b) KEGG pathway enrichment of DEGs of glomerulus. (c) GO analysis of DEGs of tubulointerstitial. (d) KEGG pathway enrichment of DEGs of tubulointerstitial. GO, gene ontology; KEGG, Kyoto Encyclopedia of Genes and Genomes. 
a

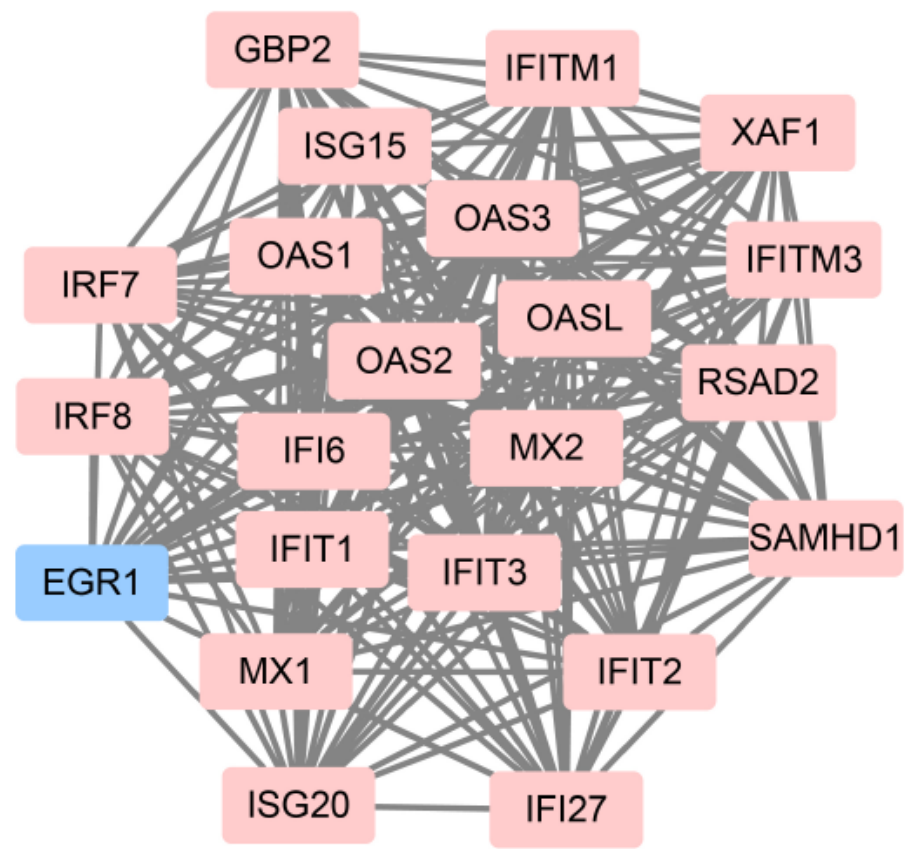

b

Tubulointerstitial

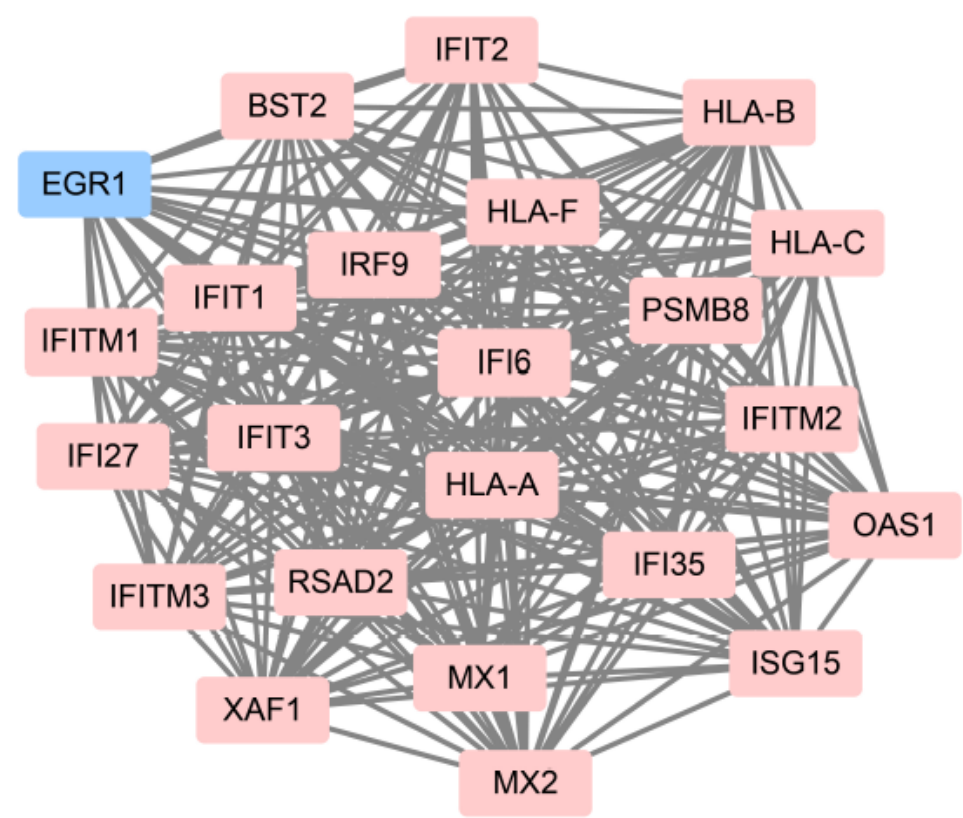

\section{Figure 3}

The key modules of the PPI network of DEGs. (a) The most significant module in PPI network of glomeruli. (b) The most significant module in PPI network of tubulointerstitial. Red nodes denoted upregulated DEGs, blue nodes denoted downregulated DEGs. PPI, protein-protein interaction network.
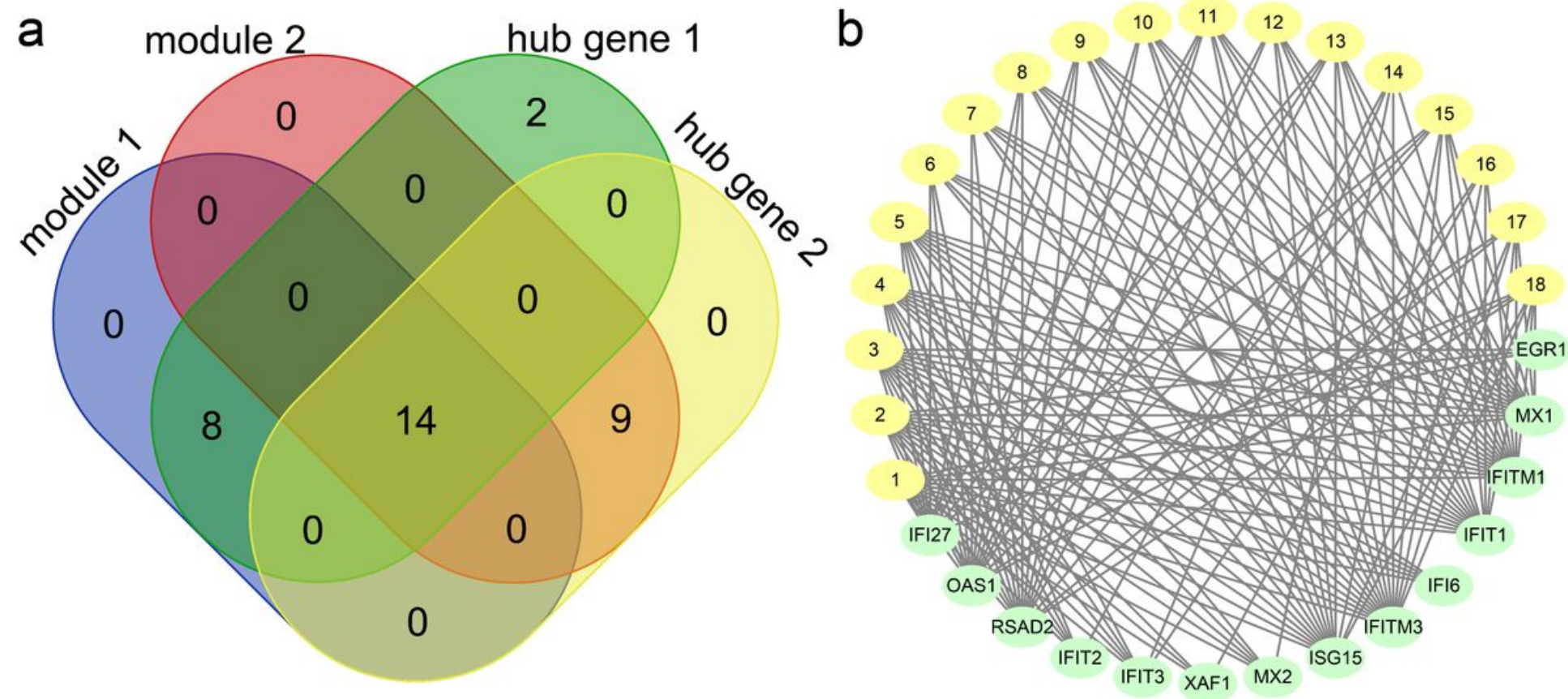

\section{Figure 4}

Hub genes identification and functional enrichment analysis. (a) Venn diagram showing 14 overlap genes from 4 groups. (b) GO analysis of 14 hub genes. 
a Glomeruli

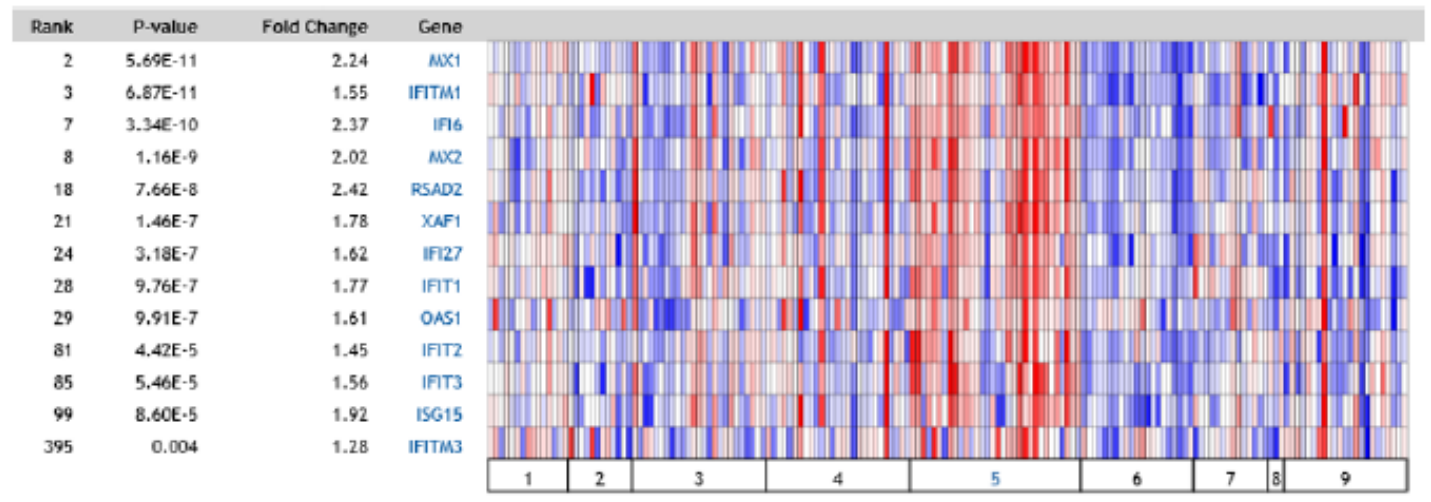

b Tubulointerstitial

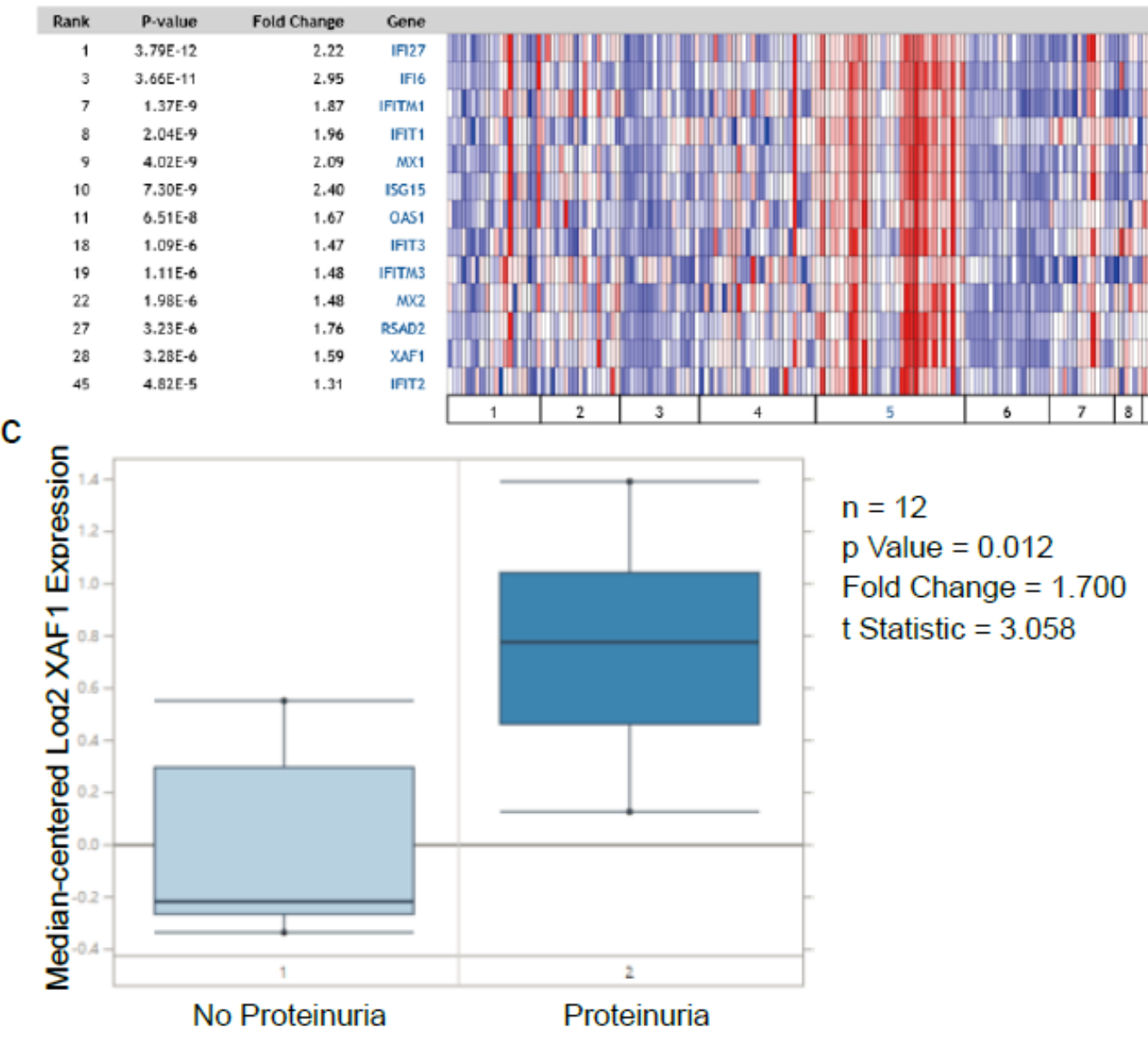

Figure 5

Analysis of the DEGs using Nephroseq database. (a) The expression of the 13 upregulated genes in glomeruli. (b) The expression of the 13 upregulated genes in tubulointerstitial. (c) The expression of XAF1 in lupus mouse model with no proteinuria or proteinuria. 


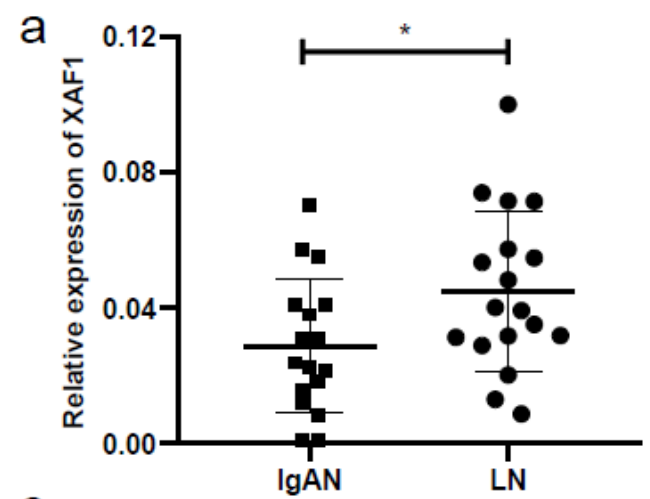

C

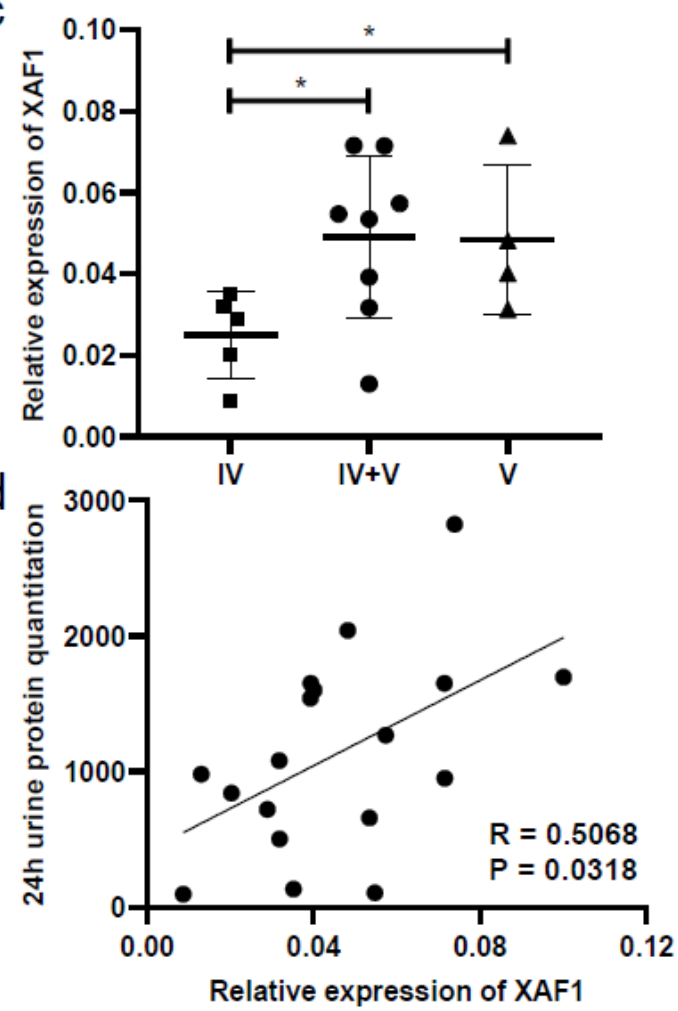

b
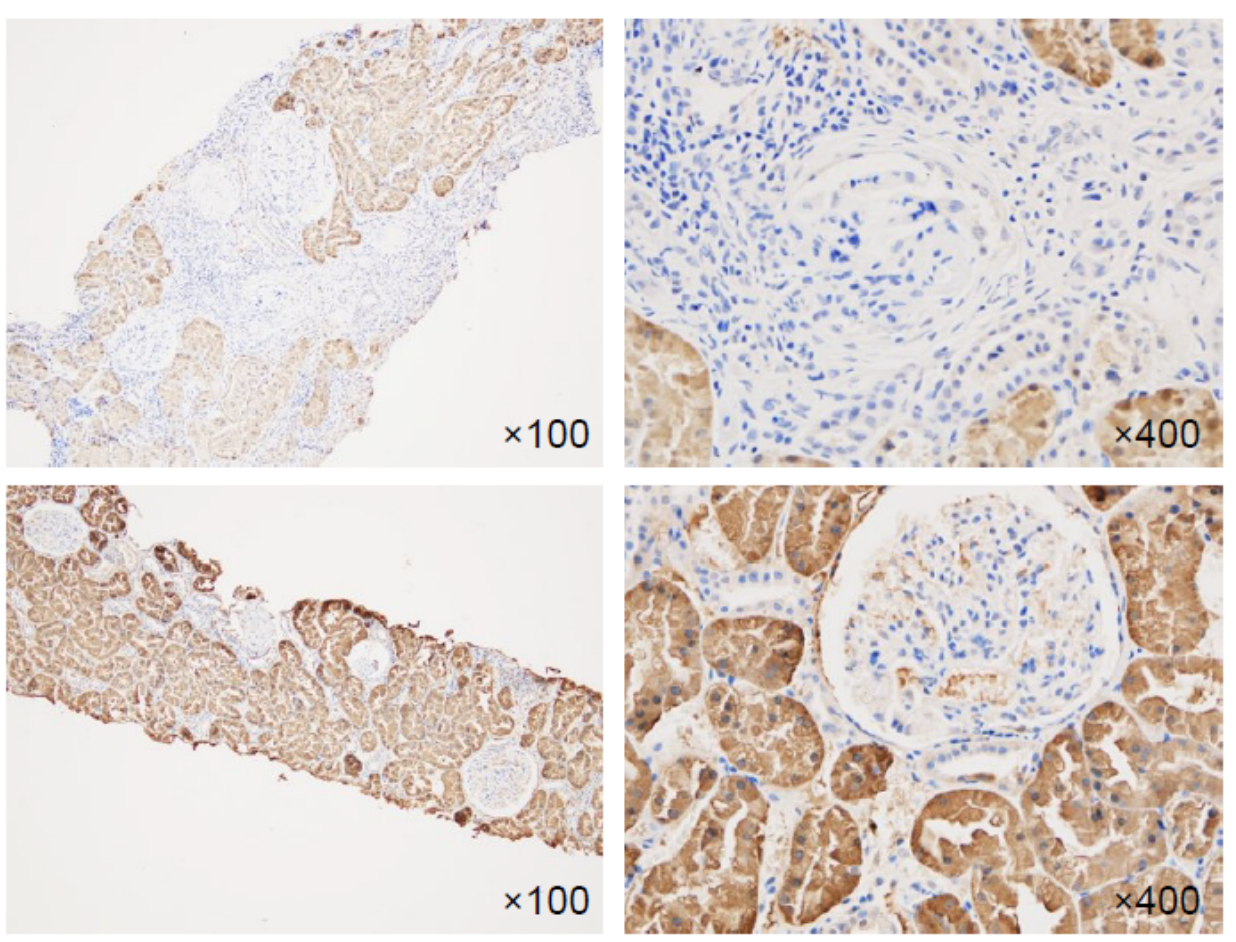

Figure 6

The expression of XAF1 in renal tissues and the correlations with the clinical characteristics. (a) The expression level of XAF1 in renal tissues of IgAN and LN based on IHC. (b) Representative images of IHC of XAF1 in IgAN and LN renal tissues (c) The expression level of XAF1 in different WHO Lupus Nephritis Class. (d) The expression of XAF1 shows a positive correlation with proteinuria. *P区 0.05 .

\section{Supplementary Files}

This is a list of supplementary files associated with this preprint. Click to download.

- tableS1.docx

- FIGS1.pdf 